\title{
Vertical distribution of phytoplankton and primary production in relation to nutricline depth in the open ocean
}

\author{
Katherine Richardson ${ }^{1, *}$, Jørgen Bendtsen ${ }^{2}$ \\ ${ }^{1}$ Center for Macroecology, Evolution and Climate, Department of Biology, University of Copenhagen, \\ 2100 Copenhagen O, Denmark \\ ${ }^{2}$ ClimateLab, Symbion Science Park, 2100 Copenhagen O, Denmark
}

\begin{abstract}
Global ocean primary production (PP) is a function of both light and nutrient availability. The vertical distribution of nutrients in the euphotic zone differs in both time and space. As a result, the vertical distribution of PP varies as well. Differences in the vertical distribution of PP have not, however, been systematically studied. Here, we focus on the open ocean and use nutricline depth, $\mathrm{D}_{\mathrm{NO}}$ (defined as the depth where $\left[\mathrm{NO}_{3}{ }^{-}\right]=1 \mu \mathrm{mol} \mathrm{\textrm {kg } ^ { - 1 }}$ ), as a proxy for nutrient availability in the euphotic zone. Using our own and archived (WOD, HOT, BATS, CARIACO) data, we show universal relationships between $\mathrm{D}_{\mathrm{NO} 3}$ and (1) depth of the deep chlorophyll maximum (DCM), (2) total water column PP and (3) vertical distribution of PP. When $\mathrm{D}_{\mathrm{NO} 3}$ is located between $\sim 20$ and $90 \mathrm{~m}$, the DCM and $\mathrm{D}_{\mathrm{NO} 3}$ are juxtaposed. However, the DCM is located above nutriclines found at $>\sim 90 \mathrm{~m}$. The observed relationships between $\mathrm{DCM}$ and $\mathrm{D}_{\mathrm{NO} 3}$ depths can be explained with a simple model including light and nutrient limitation. The global PP estimates indicate that $\sim 25 \%$ of ocean PP occurs in the upper $10 \mathrm{~m}$. Estimating total global ocean PP from surface optical characteristics and the relationship between vertical PP distribution and $\mathrm{D}_{\mathrm{NO} 3}$ indicates that oligotrophic regions of the ocean may be more productive than usually assumed. The relationship shown here between water column $\mathrm{PP}$ and $\mathrm{D}_{\mathrm{NO} 3}$ suggests that considering stratification characteristics in a future ocean is critical for predicting climate change effects on global PP.
\end{abstract}

KEY WORDS: Global primary production · Vertical distribution · Deep chlorophyll maximum . Nutricline

\section{INTRODUCTION}

Light and nutrients are prerequisites for photosynthesis. In the ocean, light enters through the surface and is attenuated exponentially with depth. Nutrient concentrations, on the other hand, tend to increase with depth in many regions. In seasonally or permanently stratified water columns, inorganic nutrient concentrations in the well-lit surface waters can be so low as to be undetectable using standard methods. Under such conditions, photosynthesis can only be supported by nutrients regenerated in the surface

\footnotetext{
*Corresponding author: kari@science.ku.dk
}

waters, diazotrophy, or by gaining access to nutrients from deeper in the water column.

As a result, it is often assumed that climate changeinduced warming of the surface ocean will lead to a decrease in ocean photosynthesis or primary production (PP) by increasing stratification, thereby reducing the probability of mixing events bringing nutrients from deep ocean layers into the surface waters (e.g. Cabré et al. 2015). In fact, however, it is not clear if/how such changes in water column stratification will influence PP in different ocean regions. Indeed, a modelling study of the permanently stratified Sar-

() The authors 2019. Open Access under Creative Commons by Attribution Licence. Use, distribution and reproduction are unrestricted. Authors and original publication must be credited. 
gasso Sea (Richardson \& Bendtsen 2017) has suggested that changes in the intensity of thermal stratification would likely have little or no impact on PP in this region.

In all regions of the world's oceans where water column stratification occurs, the maximum chlorophyll concentration in the water column is often found well below the surface. In some cases, these deep chlorophyll maxima (DCMs) have been shown to contribute significantly to total water column PP (arctic: Richardson et al. 2005, Martin et al. 2013; temperate: Weston et al. 2005, Hickman et al. 2012, Fernand et al. 2013, Lyngsgaard et al. 2014; subtropical: Fawcett et al. 2014, Richardson et al. 2014). DCMs are often, but not always, positioned in or near the nutricline, and this has often been interpreted as the DCM being vertically positioned so that access to both light and nutrients is maximised (Klausmeier \& Litchman 2001, Fennel \& Boss 2003, Cullen 2015). However, the mechanism(s) leading to the co-location of the DCM and the nutricline is/are not well understood.

The widespread occurrence of DCMs suggests they are of potential ecological importance. One aim of this study was therefore to examine their global distribution in relation to nutrient availability. Adaptation to low light can lead to physiological adaptations which may lead to changes in the amount of chlorophyll per cell (e.g. Richardson et al. 1983) as well as the cellular carbon:chlorophyll ratio (e.g. Fennel \& Boss 2003). Thus, the DCM does not necessarily represent a biomass maximum (Cullen 1982). This study therefore makes no assumptions about biomass but treats the formation of a DCM itself as the biological response under investigation.

We analyse the DCM depth in relation to the nutricline depth, $\mathrm{D}_{\mathrm{NO} 3}$ (defined on the basis of nitrate distribution, i.e. the depth where $\left[\mathrm{NO}_{3}{ }^{-}\right]=1 \mu \mathrm{mol} \mathrm{kg}{ }^{-1}$ ). We also explore the relationship between $\mathrm{D}_{\mathrm{NO} 3}$ and total water column PP and the vertical distribution of PP in the open ocean. The initial analyses were carried out on data from a globally circumnavigating cruise. These indicated clear relationships between (1) the depth of the DCM, (2) total water column PP and (3) the vertical distribution of $\mathrm{PP}$ and $\mathrm{D}_{\mathrm{NO} 3}$. However, our own data set was too limited to conclude that the patterns found are valid for the global open ocean. To assess the universality of the patterns identified, we therefore extended the analyses to include archived data.

All of the patterns found in the analysis of our own data set were corroborated by the analyses of the archived data. The relationship between the DCM and $\mathrm{D}_{\mathrm{NO} 3}$ depth is analysed in a simple vertical bal- ance model. Finally, we apply the relationship between surface production and total production to make an estimate of global PP and discuss this in relation to other satellite-derived global PP estimates.

\section{MATERIALS AND METHODS}

\subsection{Collection and analysis of own data}

Data collected on the Galathea3 expedition (www. galathea3.dk), which circumnavigated the globe in 2006-2007, comprised the major part of our dataset. These data were supplemented for the analysis with data from 2 cruises with RV 'Dana' in the North Atlantic (August 2008 and September 2012). Coastal stations, where terrestrial nutrient input can complicate interpretation of nutrient dynamics, were not included in the study. The data set employed is comprised of 124 stations, where the majority (81) were open-ocean, deep-water (>1000 m) stations from all major ocean basins except the North Pacific (Fig. 1). The data set consisted of PP estimates made at $>100$ stations where the sample collection, ${ }^{14} \mathrm{C}$ uptake incubations, determination of photosynthetic parameters, and estimates of vertical profiles of PP were made using identical equipment and protocols. Thus, errors associated with operator and protocol (Richardson 1991) were minimised. This data set is further unique in that photosynthetic parameters were determined both in surface waters and in the DCM (when present). To our knowledge, this is the only existing data set that includes measurements of photosynthetic parameters from the DCM on such a large geographic scale.

Positions of the stations and detailed descriptions of the procedures used for establishing the depth of the DCM, nutrient and PP determination on all 3 of these cruises are found in Hilligsøe et al. (2011). Two photosynthetic parameters were examined: $\mathrm{P}_{\max }^{\mathrm{B}}$ the maximum rate of photosynthesis, and $\alpha^{\mathrm{B}}$, the slope of the photosynthesis vs. irradiance (P vs. E) curve, in the range where increasing light increases photosynthesis. Both are normalised to chlorophyll a (chl a) content. These parameters were derived from P vs. E curves generated from laboratory incubations $(2 \mathrm{~h})$ made on water samples collected in surface waters (5 or $10 \mathrm{~m}$ depending on latitude) and at the depth of the DCM. Differences between surface and DCM values were analysed by Student's $t$-test, and variations between the 3 nutricline intervals were analysed by ANOVA. In these analyses, results were considered significant at $\mathrm{p}<0.05$. 


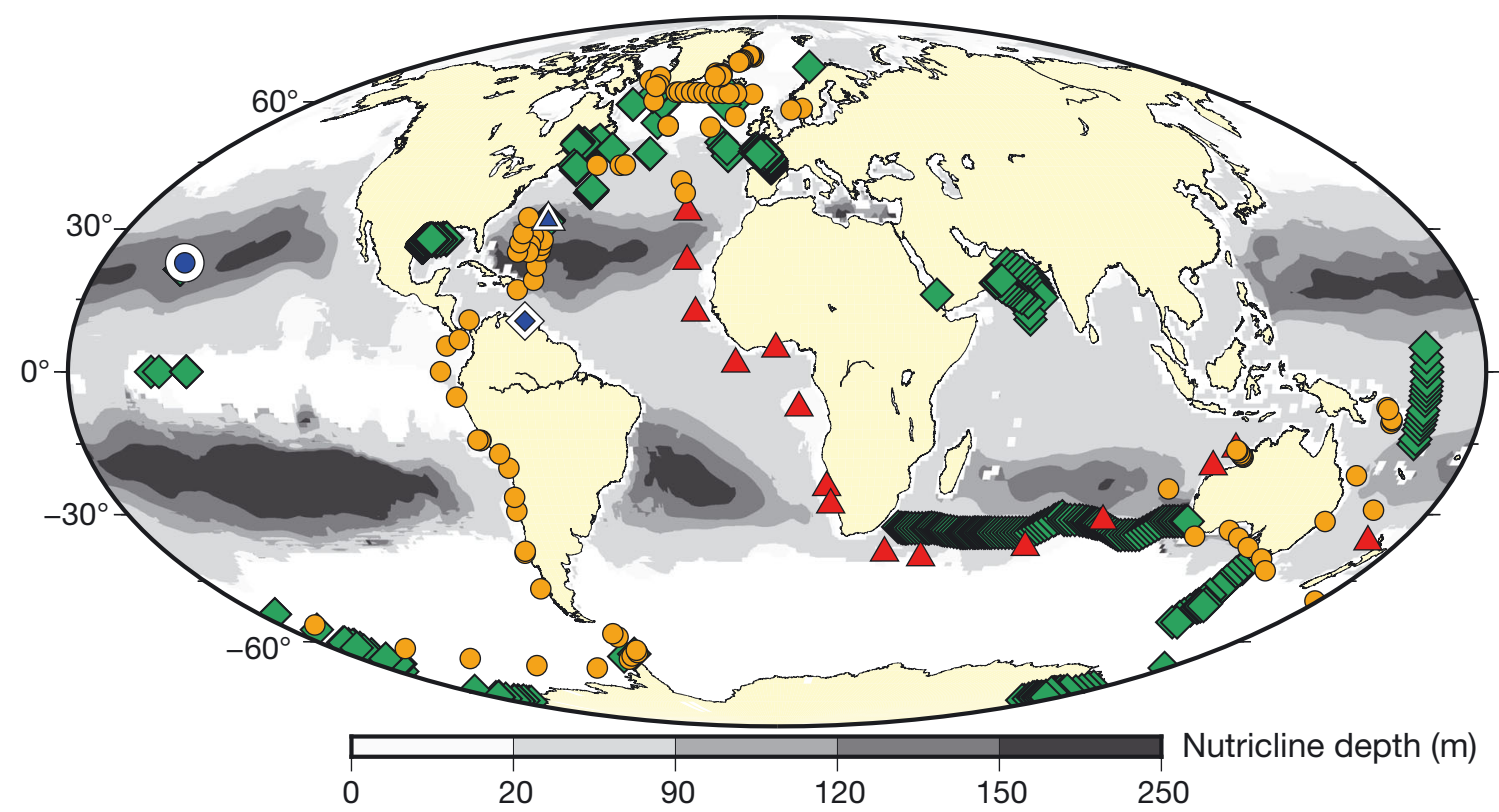

Fig. 1. Stations used in the data analyses to examine total primary production (PP) and vertical distribution of integrated PP. In our field studies reported here (orange circles), PP was calculated from photosynthetic parameters derived from incubations of samples taken in the surface and the deep chlorophyll maximum (DCM) (red triangles depict stations where only photosynthetic parameters were determined and no PP was calculated). The 3 time series stations HOT, CARIACO and BATS (shown with blue circle, diamond and triangle, respectively) used to examine vertical PP are also shown. To determine the global relationship between DCM depth and the nutricline depth $\left(\mathrm{D}_{\mathrm{NO} 3}\right)$, the field data, the time series data and archived data from the World Ocean Atlas (WOD, green diamonds) were used. Nutricline depth, based on annual climatological nitrate fields is shown with grey shading (white areas are where surface nitrate $>1 \mu \mathrm{mol} \mathrm{kg}{ }^{-1}$ )

When a DCM was not present, a second depth (usually $20 \mathrm{~m}$ ) was arbitrarily chosen in order to determine photosynthetic parameters to apply to the deeper parts of the water column at these stations. Only ${ }^{14} \mathrm{C}$ incorporated into particulate material, i.e. that associated with material retained on a Whatman GFF filter, is included in the PP estimates. Accumulated PP through the water column (i.e. vertical distribution of PP) was made by generating PP vs. light (E) matrices for the water column at $0.5 \mathrm{~m}$ intervals, using weekly average hourly surface irradiance (i.e. observed irradiance on the sampling day \pm 3 d) and applying station-specific light attenuation coefficients (Hilligsøe et al. 2011).

Photosynthetic parameters obtained from the surface samples were assumed to apply for the phytoplankton community to the bottom of the mixed layer, identified from hydrographic profiles, and photosynthetic parameters from the DCM were assumed to represent conditions deeper in the water column. Applying these different photosynthetic parameters to different depth intervals in the water column corrects, at least to some extent, for the influence of changing light conditions (both with respect to intensity and spectral composition) on photosynthetic performance. The profile of accumulated PP from the surface to the bottom of the euphotic zone, defined as the depth of penetration of $0.1 \%$ of the surface irradiance, was used to describe the vertical distribution of PP. Differences in the vertical distribution of PP between stations were identified by comparing the percentage of total water column PP estimated to occur in the upper $10 \mathrm{~m}$ and below at each station.

Nutricline depth $\left(\mathrm{D}_{\mathrm{NO} 3}\right)$ was defined as the depth where $\left[\mathrm{NO}_{3}{ }^{-}\right]=1 \mu \mathrm{mol} \mathrm{kg}{ }^{-1}$. When not explicitly sampled, this depth was found by linear interpolation between the 2 sampling depths where $\left[\mathrm{NO}_{3}{ }^{-}\right]$was, respectively, above and below $1 \mu \mathrm{mol} \mathrm{kg}{ }^{-1}$. Therefore, 'nutricline depth' as used in this study refers to the shallowest depth at which $\left[\mathrm{NO}_{3}{ }^{-}\right]$concentration is measured or interpolated to be $1 \mu \mathrm{mol} \mathrm{kg}^{-1}$.

\subsection{Analysis of archived data}

To test the universality of the relationship between $\mathrm{D}_{\mathrm{NO} 3}$ and depth of the DCM found in our dataset, we examined the vertical distribution of chl a fluorescence in relation to $\mathrm{D}_{\mathrm{NO} 3}$ from the global World 
Ocean Database (WOD) data set and 3 time series stations (Hawaii Ocean Time-series [HOT], Bermuda Atlantic Time-series Study [BATS] and Carbon Retention in a Colored Ocean [CARIACO]), respectively (Fig. 1). While the data from the time series stations do not greatly increase the geographic distribution of data points, they do ensure a good seasonal representation in the extended data set. It is difficult to find archived PP estimates from which the vertical distribution of PP at the sampling station can be discerned. However, because the sampling protocols for all 3 of these time series stations call for in situ determination of $\mathrm{PP}$, i.e. samples collected at specific depths are returned to those depths for incubation with ${ }^{14} \mathrm{CO}_{2}$, it was also possible to estimate the vertical distribution of PP at the time series stations. Furthermore, the fact that in situ incubations are used for these time series studies means that effects of changing light conditions, both intensity and spectral distribution, are accounted for in these PP estimates.

When examining the archived data, the nutricline depth was calculated as described above. Only profiles with more than 4 bottle depths were used, and the DCM was identified as the maximum value in the fluorescence-derived chl a profile. The WOD dataset is described by Boyer et al. (2013). All (898) highresolution pairs of CTD profiles with chl a (i.e. fluorescence-derived and ocean depth $>30 \mathrm{~m}$ ) and bottle data with nitrate (i.e. $>4$ bottle depths) from the period 1990-2017 were analysed. The data covered the North Atlantic, Indian Ocean, tropical and South Pacific and the Southern Ocean.

The HOT station (Karl \& Lukas 1996) is located in the oligotrophic northern Pacific $\left(22^{\circ} 45^{\prime} \mathrm{N}, 158^{\circ} \mathrm{W}\right)$. Bottle data of nitrate+nitrite, CTD data with chl a profiles and PP from the period 1988-2014 were obtained via the online HOT Data Organization \& Graphical System (HOT-DOGS) extraction (Fujieki et al. 2007); the nutricline depth was determined from the combined nitrate+nitrite samples, and inspection of nitrite values showed that they made a negligible contribution to the calculation of $\mathrm{D}_{\mathrm{NO} 3}$. For these data, $\mathrm{D}_{\mathrm{NO}}$ was determined as above when sufficient nutrient samplings were available. The DCM depth was estimated from the CTD-fluorescence data (only CTD-casts made within $1 \mathrm{~d}$ of the bottle sampling were included, resulting in $\mathrm{n}=190$ pairs of DCM depth and $\mathrm{D}_{\mathrm{NO} 3}$ ).

The BATS station (Lomas et al. 2013) data were collected in the oligotrophic Sargasso Sea (31 $50^{\prime} \mathrm{N}$, $\left.64^{\circ} 10^{\prime} \mathrm{W}\right)$. BATS discrete bottle data, PP data and CTD-profiles were analysed for the period 1988$2016(n=294)$.
The CARIACO time series station (Scranton et al. 2014) is located in a relatively high productive upwelling area in the Cariaco Basin on the shelf towards the Caribbean Sea $\left(10^{\circ} 30^{\prime} \mathrm{N}, 64^{\circ} 40^{\prime} \mathrm{W}\right)$. CARIACO discrete bottle data, PP data and CTDprofiles were analysed for the period 1995-2016 (n = 94).

All 3 time-series stations have a relatively high vertical resolution of PP measurements (typically 6-8 samples in the upper 100-140 m), collected via in situ incubations, and all stations applied the ${ }^{14} \mathrm{C}$-tracer method (modified from Steemann Nielsen 1952) also used in our own data collection. Vertical PP was calculated by trapezoidal integration between the upper sample (assuming constant values between 0 and $5 \mathrm{~m}$ ) and the bottom sample (the profile was only considered if the bottom depth was below $100 \mathrm{~m}$ at HOT and BATS and below $80 \mathrm{~m}$ at the CARIACO station).

\subsection{Estimation of PP}

Total water column PP was estimated according to Webb et al. (1974):

$\mathrm{PP}=\int_{0}^{24 \mathrm{~h}} \int_{z_{\mathrm{D}}}^{0} \mathrm{P}_{\max }^{\mathrm{B}} \operatorname{chl}(z)\left(1-\exp \left(-\mathrm{PAR}(t, z) \alpha^{\mathrm{B}} / \mathrm{P}_{\max }^{\mathrm{B}}\right)\right) \mathrm{d} z \mathrm{~d} t$

where $t$ is time, $z$ is the vertical coordinate, and $z_{\mathrm{D}}$ is the lower depth level. PP is integrated from the euphotic depth (i.e. $z_{\mathrm{D}}=z_{\text {eup }}$ ) to the surface and, when integrated over $24 \mathrm{~h}$ using the daily insolation curve of photosynthetically active radiation (PAR), this provides the total daily PP (e.g. in units of mg C $\mathrm{m}^{-2}$ ). The chlorophyll and PAR distribution vary with depth, and the PP calculation includes depth variation of both chlorophyll and the photosynthetic parameters. However, limited information on the depth variation of these parameters often requires a simple parameterisation of their depth-dependence. For example, the calculation of total PP in the water column parameterises the photosynthetic parameters by assuming that their values at the surface (i.e. at $5 \mathrm{~m}$ depth) are representative for the mixed layer and that values obtained from incubations of water at the DCM are representative of the water below (Hilligsøe et al. 2011). PP estimates obtained from the archived data were based on in situ incubations made at discrete depths. In this case, total PP is estimated by assuming photosynthetic rates obtained are valid for specific depth intervals and then summing the resulting estimates for the water column as a whole. 
Table 1. Distribution of photosynthetic parameters $\left(\alpha^{\mathrm{B}}\right.$ : slope of the photosynthesis vs. irradiance curve; $\mathrm{P}^{\mathrm{B}}$ max: maximum rate of photosynthesis). Mean \pm SE (number of samples in parentheses) of photosynthetic parameters and the fraction of accumulated primary production (PP) above $10 \mathrm{~m}$ in intervals of nutricline depths. Differences between surface and deep chlorophyll maximum (DCM) values were analysed by Student's $t$-test (significant values of $p<0.05$ are marked with superscript ' $v$ '), and variations between the 3 nutricline depth intervals were analysed by ANOVA, with significantly $(p<0.05)$ different mean values indicated by superscript ' $h$ '

\begin{tabular}{|c|c|c|c|c|c|c|c|}
\hline $\begin{array}{l}\mathrm{D}_{\mathrm{NO} 3} \text { depth } \\
\text { (m) }\end{array}$ & 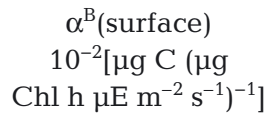 & 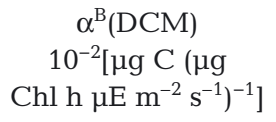 & $\underset{\left(\alpha^{\mathrm{B}}\right)}{\mathrm{p}}$ & $\begin{array}{c}\mathrm{P}^{\mathrm{B}}{ }_{\max }(\text { surface }) \\
{\left[\mu \mathrm{C} \mathrm{C}(\mu \mathrm{g} \mathrm{Chl} \mathrm{h})^{-1}\right]}\end{array}$ & $\begin{array}{c}\mathrm{P}^{\mathrm{B}}{ }_{\max }(\mathrm{DCM}) \\
{\left[\mu \mathrm{g} \mathrm{C}(\mu \mathrm{g} \mathrm{Chl} \mathrm{h})^{-1}\right]}\end{array}$ & $\underset{\left(\mathrm{P}^{\mathrm{B}}{ }_{\max }\right)}{\mathrm{p}}$ & $\begin{array}{l}\text { Acc. PP } \\
\text { above } \\
10 \mathrm{~m}(\%)\end{array}$ \\
\hline$\leq 20$ & $3.57 \pm 0.38(63)$ & $4.63 \pm 0.60(45)$ & 0.122 & $2.57 \pm 0.22(63)$ & $2.03 \pm 0.23(45)$ & 0.100 & $31.0 \pm 2.3(61)$ \\
\hline $20-90$ & $2.68 \pm 0.40$ & $3.61 \pm 0.50(32)$ & 0.152 & $3.29 \pm 0.32$ & $1.62 \pm 0.17(32)$ & $<10^{-4 \mathrm{v}}$ & $19.0 \pm 2.4(30)$ \\
\hline$>90$ & $1.59 \pm 0.23(18)^{\mathrm{h}}$ & $3.29 \pm 0.57(16)$ & $0.009^{v}$ & $2.73 \pm 0.45(18)$ & $1.06 \pm 0.15(16)^{\mathrm{h}}$ & $0.002^{\mathrm{v}}$ & $10.7 \pm 1.6(15)$ \\
\hline
\end{tabular}

\subsection{Estimation of global PP using the vertical distribution of PP}

To estimate global PP based on the pattern of PP vertical distribution determined here, the $\mathrm{PP}$ in the upper $10 \mathrm{~m}\left(\mathrm{PP}_{0-10 \mathrm{~m}}\right)$ was first estimated using Eq. (1) and integrating only to $10 \mathrm{~m}$ (i.e. $z_{\mathrm{D}}=-10 \mathrm{~m}$ ). Surface ocean data collected with satellite-based sensors were obtained from the Ocean Productivity site (www. science.oregonstate.edu/ocean.productivity). These data covered the globe in a 1/12 × 1/12 degree spherical grid and were averaged for $8 \mathrm{~d}$ periods. Satellite data of sea surface temperature, PAR, surface chl $a$ and the diffuse attenuation coefficient in the $490 \mathrm{~nm}$ band $\left(k_{\mathrm{d}} 490\right)$ were applied in the period 2003-2013 (MODIS data provided by NASA). The diffuse attenuation coefficient in the upper $10 \mathrm{~m}$ was calculated from $k_{\mathrm{d}} 490$ in accordance with Morel et al. (2007).

The chl a concentration was assumed to be constant in the upper $10 \mathrm{~m}$ and is represented by the satellitederived chl a values. The time-dependence of surface PAR during the day was calculated following the description in Luyten et al. (1999), where the hourly clear sky insolation was calculated on Day 1 of every $8 \mathrm{~d}$ period at each grid point, and the total insolation during the day was then scaled such that the resulting daily insolation was equal to the satellite-derived surface PAR. The vertical PAR distribution $(\operatorname{PAR}(t, z))$ in the upper $10 \mathrm{~m}$ was calculated from the surface PAR and the diffuse light attenuation coefficient. In order to facilitate direct comparison between these estimates and those obtained using more traditional algorithms for estimating global PP from surface optical characteristics, we applied the photosynthetic parameter $\left(\mathrm{P}_{\text {max }}^{\mathrm{B}}\right)$ describing the light vs. photosynthesis relationship used in one of the standard algorithms (i.e. the vertically generalized production model, VGPM; cf. Eq. [11] in Behrenfeld \& Falkowski (1997), where $\mathrm{P}^{\mathrm{B}}{ }_{\text {opt }}$ represents $\mathrm{P}_{\text {max }}^{\mathrm{B}}$ and is parameterised from sea surface temperature). The value of $\alpha^{\mathrm{B}}$ was obtained from the surface values in Table 1. The global distribution of $\mathrm{D}_{\mathrm{NO} 3}$ was determined from the global monthly climatology of nitrate in the World Ocean Atlas (Garcia et al. 2010). Daily PP in the upper $10 \mathrm{~m}$ was calculated in this manner from Eq. (1) by integrating over depth and time $(24 \mathrm{~h})$ at every grid cell. We then calculated the annual averaged field of PP in the period 2003-2013 in the upper $10 \mathrm{~m}$.

The model calculation of $\mathrm{PP}_{0-10 \mathrm{~m}}$ was then extended to provide an estimate of the total vertically integrated global PP (VPP). VPP was calculated separately for regions where $\mathrm{D}_{\mathrm{NO} 3}<20,20-90$ and $>90 \mathrm{~m}$ by assuming that the average ratio $(\gamma)$ obtained from our observations for each region, and defined as the ratio between the surface production in the upper $10 \mathrm{~m}$ and the total production in the water column, was representative for all areas with the selected $\mathrm{D}_{\mathrm{NO} 3}$ ranges. In oligotrophic areas $\left(\mathrm{D}_{\mathrm{NO} 3}>90 \mathrm{~m}\right)$, for example, production above $10 \mathrm{~m}$ corresponded to $\gamma=$ $10.7 \%$ of the total production, i.e. $\mathrm{PP}_{0-10 \mathrm{~m}}=\gamma \mathrm{VPP}$ (Table 2). Thus, in these areas, the VPP was about a factor of 10 larger than the surface PP.

Table 2. Global primary production in the upper $10 \mathrm{~m}$ $\left(\mathrm{PP}_{0-10 \mathrm{~m}}\right)$ calculated from satellite-derived surface fields in the 3 nutricline depth intervals. Data-derived ratio $(\gamma)$ of $\mathrm{PP}_{0-10 \mathrm{~m}}$ to total PP derived from data (see Section 2.4) is used for estimating total global PP from $\mathrm{PP}_{0-10 \mathrm{~m}}$ (VPP). For comparison, global PP is also calculated by the VGPM model of Behrenfeld \& Falkowski (1997) ( PP $\left._{\text {VGPM }}\right)$. All calculations are based on photosynthetic parameters applied in the VGPM model. Means $\pm \mathrm{SE}$ are shown for $\gamma$ (number of samples in parentheses), and means $\pm \mathrm{SD}$ from all $8 \mathrm{~d}$ periods in 2003-2013 ( $\mathrm{n}=506$ ) are shown for the global VPP and $\mathrm{PP}_{\text {VGPM }}$ estimates

\begin{tabular}{|c|c|c|c|c|}
\hline $\begin{array}{l}\mathrm{D}_{\mathrm{NO} 3} \\
\text { depth (m }\end{array}$ & $\begin{array}{c}\gamma \\
(\%)\end{array}$ & $\begin{array}{c}\mathrm{PP}_{0-10 \mathrm{~m}} \\
\left(\mathrm{Pg} \mathrm{C}_{\mathrm{yr}^{-1}}\right)\end{array}$ & $\begin{array}{c}\text { VPP } \\
\left({\left.\mathrm{Pg} \mathrm{C} \mathrm{yr}^{-1}\right)}^{2}\right)\end{array}$ & $\begin{array}{c}\mathrm{PP}_{\mathrm{VGPM}} \\
\left(\mathrm{Pg} \mathrm{C}_{\mathrm{yr}^{-1}}\right)\end{array}$ \\
\hline$<20$ & $31.0 \pm 2.3(61)$ & $9.0 \pm 0.8$ & $28.7 \pm 2.4$ & $30.9 \pm 2.7$ \\
\hline $20-90$ & $19.0 \pm 2.4$ & $2.3 \pm 0.2$ & $12.2 \pm 1.1$ & $10.9 \pm 0.7$ \\
\hline$>90$ & $10.7 \pm 1.6$ & $0.9 \pm 0.1$ & $8.6 \pm 0.5$ & $6.1 \pm 0.3$ \\
\hline Total & - & $12.1 \pm 0.9$ & $49.3 \pm 3.4$ & $47.8 \pm 3.3$ \\
\hline
\end{tabular}




\subsection{Modelling the relationship between nutricline and DCM depths}

A simple model was analysed for explaining the divergence between the depth of the DCM and the nutricline with depth. The model assumes that export of sinking particulate organic matter from the euphotic zone can be described as a fraction $\left(f_{\mathrm{PP}}\right)$ of the vertically integrated PP (mol C m${ }^{-2}$ time $\left.^{-1}\right)$ in the euphotic zone. Assuming that this export represents the only sink of nitrate $(\mathrm{N})$, this would, in steady state, be balanced by a corresponding nitrate transport $\left(\mathrm{F}_{\mathrm{N}}\right.$, mol $\mathrm{N} \mathrm{m}^{-2}$ time $^{-1}$ ) into the upper layer, i.e. new production as defined by Dugdale \& Goering (1967):

$$
f_{\mathrm{PP}} \mathrm{PP}=\eta_{\mathrm{C}: \mathrm{N}} \mathrm{F}_{\mathrm{N}}
$$

where the $\eta_{\mathrm{C}: \mathrm{N}}$ is a constant ratio between carbon and nitrogen in organic matter (we applied a representative, i.e. Redfield, value of 6.6). Other sinks or sources (e.g. denitrification or diazotrophy) are disregarded in Eq. (2) as they are likely of minor importance for the positioning of the DCM.

In a simple vertical balance, where nitrate is transported by turbulent mixing, the transport can be de-

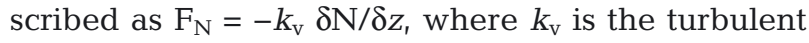
diffusion coefficient. Low nitrate concentrations, in general, characterise the upper layer of the water column in areas where $\mathrm{D}_{\mathrm{NO} 3}$ is located below the DCM (for example, see Richardson \& Bendtsen 2017) and, assuming that $\mathrm{N}(z(\mathrm{DCM})) \sim 0$ (i.e. that the nutricline lies below the DCM), the vertical nitrate gradient below the DCM can be approximated as $\delta \mathrm{N} / \delta z=$ $-\mathrm{N}\left(\mathrm{D}_{\mathrm{NO} 3}\right) /\left(z(\mathrm{DCM})-z\left(\mathrm{D}_{\mathrm{NO} 3}\right)\right)$ (note that the vertical coordinates describe the depths, e.g. $z\left(\mathrm{D}_{\mathrm{NO} 3}\right)=$ $-D_{\mathrm{NO} 3}$ ). Accordingly, the relationship in Eq. (2) between $\mathrm{D}_{\mathrm{NO} 3}$ and DCM can be described as:

$$
\mathrm{D}_{\mathrm{NO} 3}=\mathrm{DCM}+\frac{\eta_{\mathrm{C}: \mathrm{N}} k_{\mathrm{v}} \mathrm{N}\left(\mathrm{D}_{\mathrm{NO} 3}\right)}{f_{\mathrm{PP}} \mathrm{PP}}
$$

It should be noted that the vertical light dependence is included in the PP term. Thus, Eq. (3) contains both limitation from light and nutrient transports. PP was calculated according to Eq. (1) with averaged photosynthetic parameters at the DCM for nutricline depths greater than $90 \mathrm{~m}$ (Table 1). Chl a was determined from an idealised profile obtained by fitting observations along a transect in the central Sargasso Sea (Richardson \& Bendtsen 2017; along a transect at $25-30^{\circ} \mathrm{N}, 62.75^{\circ} \mathrm{W}$ ) to a Gaussian profile centered at the DCM (the best fit value for the Sargasso Sea was $126 \mathrm{~m})$, i.e. $\operatorname{chl}(z)=a_{1} \cdot \exp \left(-\left\{[z-z(\mathrm{DCM})] / a_{2}\right\}^{2}\right)$, where $a_{1}=0.165$ and $a_{2}=39.0$. Only production in the DCM was considered and, therefore, the constant background fluorescence signal in the chlorophyll profile was subtracted. Vertically integrated PP was calculated for a range of DCM values, assuming that the shape of the chl a profile remained constant, and applying a representative value of a constant surface PAR of 60 mol photons $\mathrm{m}^{-2} \mathrm{~d}^{-1}$ and a light extinction coefficient of $0.04 \mathrm{~m}^{-1}$. A reference value of $10^{-5} \mathrm{~m}^{2} \mathrm{~s}^{-1}$ was applied for the turbulent diffusion coefficient $\left(k_{V}\right)$.

\section{RESULTS}

\subsection{DCM depth vs. $\mathrm{D}_{\mathrm{NO}}$}

Similar relationships were found between DCM depth and $\mathrm{D}_{\mathrm{NO} 3}$ in our own and the archived data (Fig. $2 \mathrm{a}-\mathrm{C}$ ). In all cases, the pattern that emerged from plotting DCM depth as a function of $\mathrm{D}_{\mathrm{NO} 3}$ indicates a relationship that varies in different depth strata. Close to the surface, there is no apparent rela-
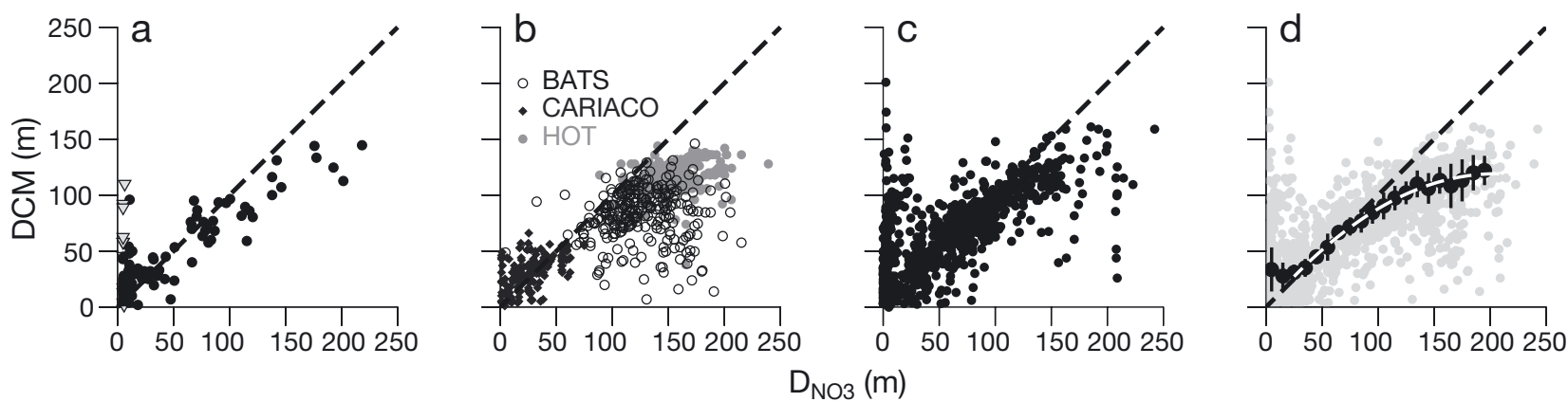

Fig. 2. DCM vs. nutricline $\left(\mathrm{D}_{\mathrm{NO} 3}\right)$ depth, calculated with data from (a) our observations (grey triangles are potential high nutrient-low chlorophyll stations in the Southern Ocean [south of $55^{\circ} \mathrm{S}$ ]), (b) 3 time series stations and (c) the World Ocean Database. (d) All pairs of DCM vs. $\mathrm{D}_{\mathrm{NO} 3}$ (light grey bullets) data were binned, and median values (bullets) and median absolute deviation (error bars) were calculated in $10 \mathrm{~m}$ intervals. Also shown are the lines $\mathrm{DCM}=\mathrm{D}_{\mathrm{NO} 3}$ (black dashed line) and a polynomial fit to the data (white dashed line). Abbreviations as in Fig. 1 
tionship between the DCM and $\mathrm{D}_{\mathrm{NO} 3}$. Below this surface layer, the DCM depth and $\mathrm{D}_{\mathrm{NO} 3}$ apparently coincide, and when $\mathrm{D}_{\mathrm{NO} 3}$ is deeper than $90 \mathrm{~m}$, the DCM is positioned above $\mathrm{D}_{\mathrm{NO} 3}$. All observations (from Fig. 2a-c) were combined to further analyse the relationship between DCM depth and $\mathrm{D}_{\mathrm{NO}}$ (Fig. 2d).

The median value and the median absolute deviation (calculated in $10 \mathrm{~m}$ bin intervals; the number of observations in the intervals ranged between 17 for depth levels deeper than $180 \mathrm{~m}$ to more than 300 in the surface bin) between the surface and $200 \mathrm{~m}$ depth overlapped with the DCM depth $=\mathrm{D}_{\mathrm{NO} 3}$ line in the depth range between 20 and $90 \mathrm{~m}$ (Fig. 2d, a polynomial fit, i.e. $\mathrm{DCM}=a \mathrm{D}_{\mathrm{NO}_{3}}{ }^{2}+b \mathrm{D}_{\mathrm{NO} 3}$, where $a=$ $-0.00283, b=1.161$, represented the data for $\mathrm{D}_{\mathrm{NO} 3}>$ $20 \mathrm{~m}$ ). When $\mathrm{D}_{\mathrm{NO} 3}$ was shallower than $20 \mathrm{~m}$, the median values were significantly above the line and also exhibited larger variation. When $\mathrm{D}_{\mathrm{NO} 3}$ was located below $90 \mathrm{~m}$, the median values fell below the line and also had a slightly larger variation than in the intermediate depth range. These depth strata $\left(D_{\mathrm{NO} 3} \leq 20,20-90 \mathrm{~m}\right.$ and $>90 \mathrm{~m}$ ) are therefore used in the following analyses.

\subsection{Explaining the divergence between DCM and nutricline depths}

The diffusive vertical balance model (Eq. 3) was investigated by applying a realistic profile of $\mathrm{chl} a$ and PP around the DCM (Fig. 3a,b). The model was solved for 2 representative levels of turbulent mixing for the stratified oligotrophic ocean and compared with the observed divergence between the DCM and
$\mathrm{D}_{\mathrm{NO} 3}$ (Fig. 3c). The reference value for the turbulent diffusion coefficient $\left(10^{-5} \mathrm{~m}^{2} \mathrm{~s}^{-1}\right)$ causes the 2 depth levels to diverge at about $120 \mathrm{~m}$, whereas a higher value $\left(5 \times 10^{-5} \mathrm{~m}^{2} \mathrm{~s}^{-1}\right)$ results in a larger separation of the 2 depth levels at $\sim 100 \mathrm{~m}$, in general accordance with observations.

Photosynthetic parameters determined from our field samples were analysed with respect to $\mathrm{D}_{\mathrm{NO} 3}$ by averaging the values in the 3 nutricline depth intervals, i.e. $\mathrm{D}_{\mathrm{NO} 3} \leq 20,20-90$ and $>90 \mathrm{~m}$ (Fig. 4 , Table 1). The photosynthetic parameters $\left(\mathrm{P}^{\mathrm{B}}{ }_{\max }, \alpha^{\mathrm{B}}\right)$ differed both when samples were grouped according to the 3 nutricline depth intervals and when samples taken in the surface waters and the DCM were compared. For all groups defined according to nutricline depth interval, $\mathrm{P}^{\mathrm{B}}{ }_{\max }$ was consistently higher and $\alpha^{\mathrm{B}}$ lower at the surface than at the depth of the DCM. This would be expected, as an adaptation to lower light intensities typically reduces $\mathrm{P}^{\mathrm{B}}{ }_{\text {max }}$ and increases $\alpha^{\mathrm{B}}$ (Richardson et al. 1983). However, only when $\mathrm{D}_{\mathrm{NO} 3}$ was deeper than $20 \mathrm{~m}$ were the differences between $\mathrm{P}^{\mathrm{B}}{ }_{\text {max }}$ in the surface waters and DCM significant. When $\mathrm{D}_{\mathrm{NO} 3}$ was deeper than $90 \mathrm{~m}, \alpha^{\mathrm{B}}$ was also significantly different between the surface and the DCM.

Surface values of $\alpha^{\mathrm{B}}$ in regions where the $\mathrm{D}_{\mathrm{NO} 3}$ was deeper than $90 \mathrm{~m}$ were significantly lower than in the 2 other regions. While the differences in surface $\mathrm{P}^{\mathrm{B}}{ }_{\max }$ were not significantly different between regions with shallow (or non-existent) and intermediate $\mathrm{D}_{\mathrm{NO}}$, we note that the highest average $\mathrm{P}^{\mathrm{B}}{ }_{\text {max }}$ was recorded in the group of stations where $\mathrm{D}_{\mathrm{NO} 3}$ was between 20 and $90 \mathrm{~m}$ (Table 1). This suggests that photoinhibition and/or other form(s) of nutrient limitation besides $\mathrm{N}$ (e.g. high nutrient-low chlorophyll [HNLC] regions)
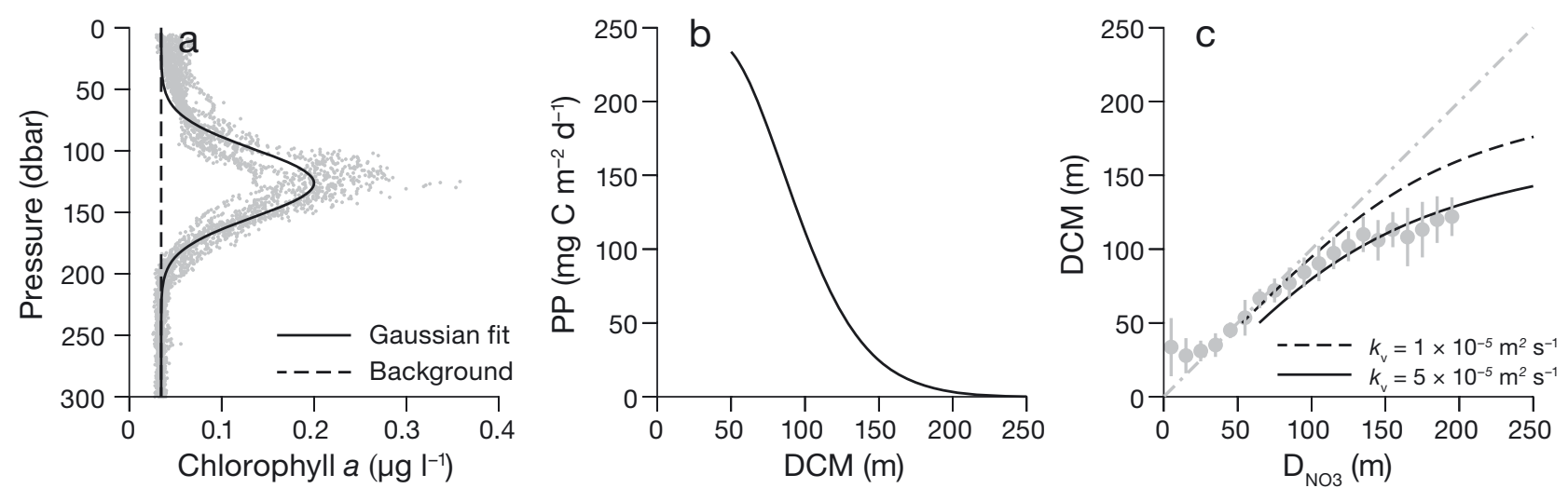

Fig. 3. (a) Gaussian profile (solid line), centered at a DCM of $126 \mathrm{~m}$, fitted to observations from the central Sargasso Sea. The constant background fluorescence (dashed line, equivalent to $0.035 \mathrm{\mu g} \mathrm{l}^{-1} \mathrm{chl} \mathrm{a}$ ) was subtracted from the profile. (b) PP calculated from Eq. (1), assuming the maximum in the chlorophyll profile was varied in a depth interval of DCM between 50 and $250 \mathrm{~m}$. (c) Solution of Eq. (3) for 2 values of the vertical turbulent diffusion coefficient $\left(k_{\mathrm{V}}\right)$ (dashed and solid lines), a Redfield $\mathrm{C}: \mathrm{N}$ ratio of 6.6 and new production $\left(f_{\mathrm{PP}}\right)$ of $10 \%$. Global averaged values of DCM vs. $\mathrm{D}_{\mathrm{NO}}$ (light grey bullets and error bars, cf. Fig. $2 \mathrm{~d}$ ) and the line $\mathrm{DCM}=\mathrm{D}_{\mathrm{NO} 3}$ are shown (light grey dashed-dotted line). Abbreviations as in Fig. 1 

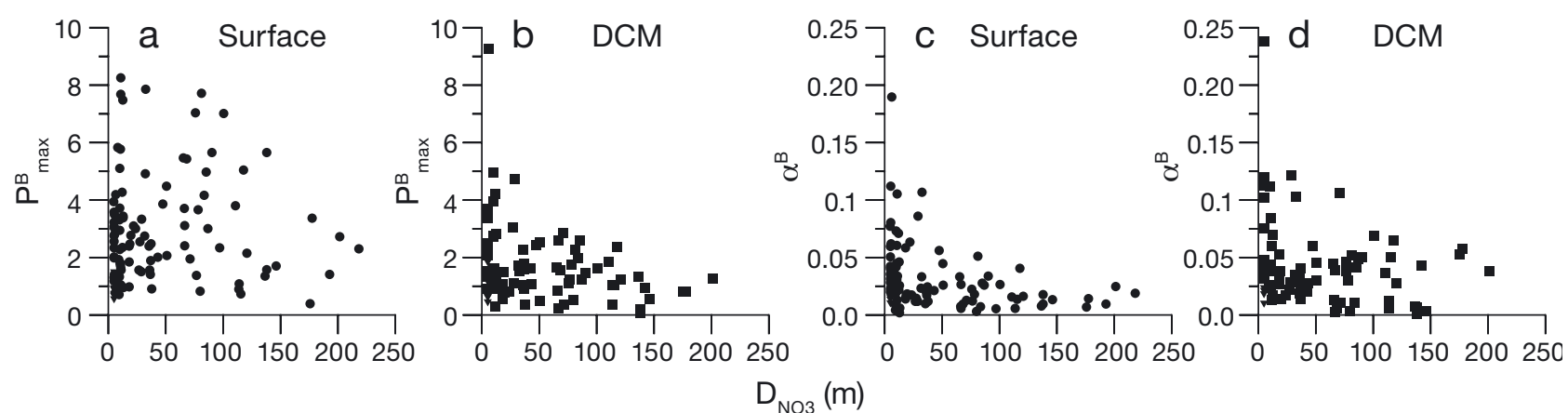

Fig. 4. Photosynthetic parameters of surface layer values (bullets) of (a) maximum rate of photosynthesis $\left(\mathrm{P}^{\mathrm{B}}\right.$ max $)$ and (c) the slope of the photosynthesis vs. irradiance curve $\left(\alpha^{\mathrm{B}}\right)$ and the corresponding values at the DCM (squares) of (b) $\mathrm{P}^{\mathrm{B}}{ }_{\max }$ and (d) $\alpha^{\mathrm{B}}$ shown versus the nutricline depth $\left(\mathrm{D}_{\mathrm{NO}}\right)$. Units of $\mathrm{P}^{\mathrm{B}}{ }_{\max }$ and $\alpha^{\mathrm{B}}$ are $\left[\mu \mathrm{g} \mathrm{C}(\mu \mathrm{g} \mathrm{Chl} \mathrm{h})^{-1}\right]$ and $\left[\mu \mathrm{g} \mathrm{C}\left(\mu \mathrm{g} \mathrm{Chl} \mathrm{h} \mu \mathrm{m}^{-2} \mathrm{~s}^{-1}\right)^{-1}\right]$, respectively. Abbreviations as in Fig. 1

could be reducing the average $\mathrm{P}^{\mathrm{B}}{ }_{\max }$ within the group of stations where the nutricline was either not present or located in the upper $20 \mathrm{~m}$. Similarly, the relatively low $\mathrm{P}_{\text {max }}^{\mathrm{B}}$ recorded for surface samples in regions where $\mathrm{D}_{\mathrm{NO} 3}$ was found at $>90 \mathrm{~m}$ again indicates nutrient limitation and/or photoinhibition in surface waters. Both $\mathrm{P}^{\mathrm{B}}{ }_{\max }$ and $\alpha^{\mathrm{B}}$ decrease with increasing $\mathrm{D}_{\mathrm{NO} 3}$ for the samples taken from the DCM.

Although seasonal differences in chlorophyll-normalised photosynthetic parameters resulting from changing light climate might be expected, we found no significant effect of season in our own data set. Our sampling days were more or less evenly distributed in relation to the longest day of the year at the sampling position in the period centered around $\pm 100 \mathrm{~d}$ around the summer solstice. This represents the most productive season in temperate and polar waters. In tropical and sub-tropical regions, we do not expect large seasonal variations. We therefore conclude that seasonal differences are not driving the patterns in the distribution of photosynthetic parameters that we found in our own dataset.

Photosynthetic parameters also fluctuate diurnally. Our own dataset is compiled from samplings made throughout the day. The highest values for $\mathrm{P}^{\mathrm{B}}$ max were recorded in surface waters for samples taken between about 08:00 and 14:00 h (Richardson et al. 2016). However, this diurnal signal was much less pronounced at the DCM than at the surface. As approximately equal numbers of our samples were taken between 08:00 and 14:00 $\mathrm{h}$ and before/after this time window, we believe that our average values for $\mathrm{P}_{\text {max }}^{\mathrm{B}}$ and $\alpha^{\mathrm{B}}$ represent reasonable approximations of averages for these parameters during the most productive part of the year. We also note that our $\mathrm{P}^{\mathrm{B}}$ max averages are in good agreement with other reports of this parameter from all parts of the global ocean (see review by Richardson et al. 2016) although somewhat lower than those used in the often applied VGPM algorithm (Behrenfeld \& Falkowski 1997) for estimating ocean PP from optical characteristics of the surface ocean.

Water column PP and chl a showed qualitatively different vertical distributions in the 3 regions characterised by nutricline depth (Fig. 5). A shallow nutricline implies that a relatively large fraction of the vertically integrated PP is located in the upper water column. Correspondingly, the chl a concentration was, in general, also greatest in the upper water column. Regions characterised by a deep nutricline, in contrast, had a larger fraction of PP found deeper in the water column and with a DCM being a consistent feature in the vertical distribution of chl $a$.

Total PP was also found to relate to $\mathrm{D}_{\mathrm{NO} 3}$ both in our own data (Fig. 6a) and those collected in the BATS, HOT and CARIACO programmes (Fig. 6b). The highest total PP was estimated for areas with a shallow nutricline with the average maximum PP decreasing by a factor of $\sim 2$ as $\mathrm{D}_{\mathrm{NO} 3}$ increases. Total PP remains relatively constant as $\mathrm{D}_{\mathrm{NO} 3}$ deepens from $\sim 100 \mathrm{~m}$. Assuming that $\mathrm{D}_{\mathrm{NO} 3}$ can be used as a proxy for nutrient availability in the euphotic zone, this decrease in PP with deepening $\mathrm{D}_{\mathrm{NO} 3}$ suggests that it is nutrient availability, i.e. the extent of overlap between nutrient-rich waters below the nutricline and the euphotic zone, that determines the magnitude of total PP in the water column.

We explored potential causes for the variability in the total PP recorded at each of the time series stations by also defining $\mathrm{D}_{\mathrm{NO} 3}$ as being equal to

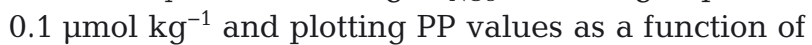
day of year for the 3 sets of time series data (Fig. 7). When $\mathrm{D}_{\mathrm{NO} 3}$ is defined as $1 \mu \mathrm{mol} \mathrm{kg}{ }^{-1}$, the nutricline is always located deep in the water column at the HOT 


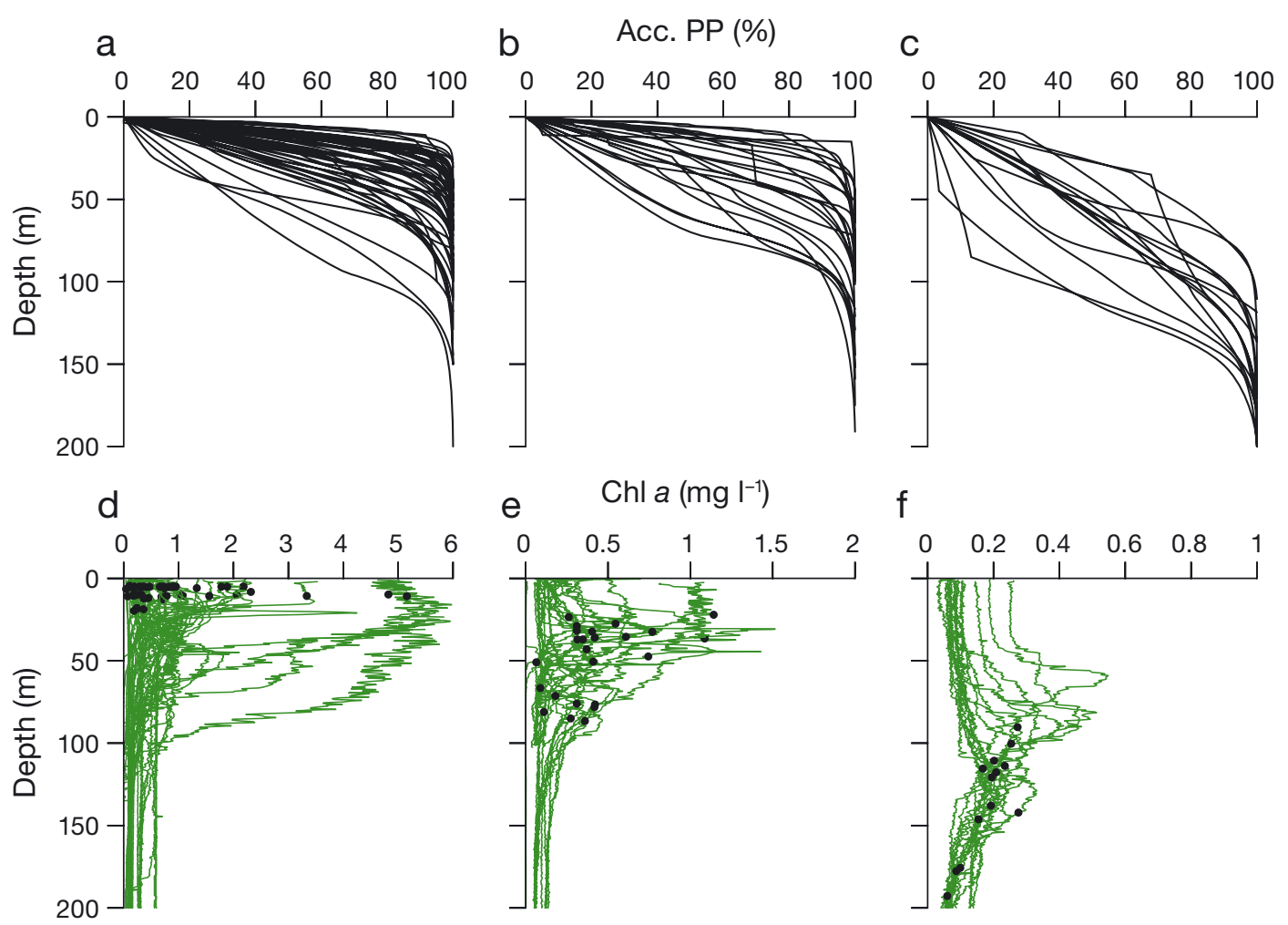

Fig. 5. (a-c) Fraction of accumulated PP and $(d-f)$ observed chl $a$ in the 3 nutricline depth intervals: $(a, d) D_{N O 3} \leq 20 \mathrm{~m},(b, e)$ $\mathrm{D}_{\mathrm{NO} 3}=20-90 \mathrm{~m}$ and $(\mathrm{c}, \mathrm{f}) \mathrm{D}_{\mathrm{NO} 3}>90 \mathrm{~m}$ ( $\mathrm{D}_{\mathrm{NO} 3}$ values are shown with bullets). Abbreviations as in Fig. 1
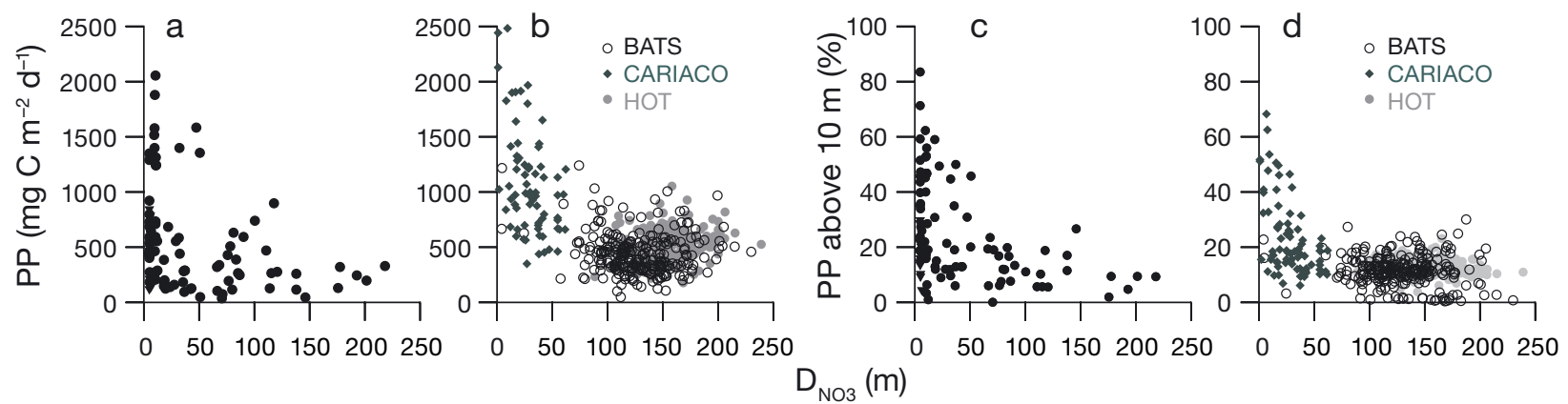

Fig. 6. (a) Total PP from observations and (b) from the 3 time series stations. (c) Fraction of PP occurring above $10 \mathrm{~m}$ versus $\mathrm{D}_{\mathrm{NO} 3}$ and (d) the corresponding values from the time series stations. Abbreviations as in Fig. 1

station. When it is defined as $0.1 \mu \mathrm{mol} \mathrm{kg}{ }^{-1}$, only a few instances are recorded where the nutricline is found higher in the water column. This suggests vertical mixing events are rare at this station. The highest PP values at the HOT station were recorded around the time of the summer solstice and the lowest in midwinter. This suggests a relatively constant nutrient environment at this station and that light may be the determining factor for the magnitude of PP.

At the BATS station, even when $\mathrm{D}_{\mathrm{NO} 3}$ is defined as

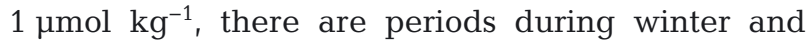
spring where the nutricline is located at $<50 \mathrm{~m}$. The number of samplings where this is the case increases dramatically when $\mathrm{D}_{\mathrm{NO} 3}$ is defined as $0.1 \mu \mathrm{mol} \mathrm{kg} \mathrm{kg}^{-1}$ (Fig. 7d). This is consistent with known seasonal patterns of mixing at this station (Steinberg et al. 2001). The periods with the shallowest nutricline coincided with the periods with the highest rates of PP. Compared to the HOT station, then, the BATS station appears to more frequently experience mixing events especially during the first part of the year. It is therefore during this period, rather than around the summer solstice, that peak PP is recorded. The CARIACO station is located in an area with frequent upwelling 
a

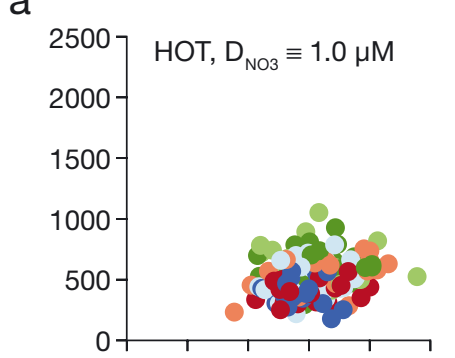

C

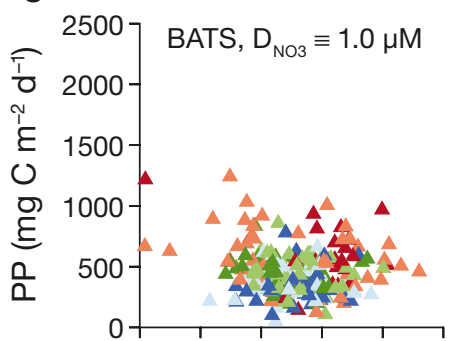

e

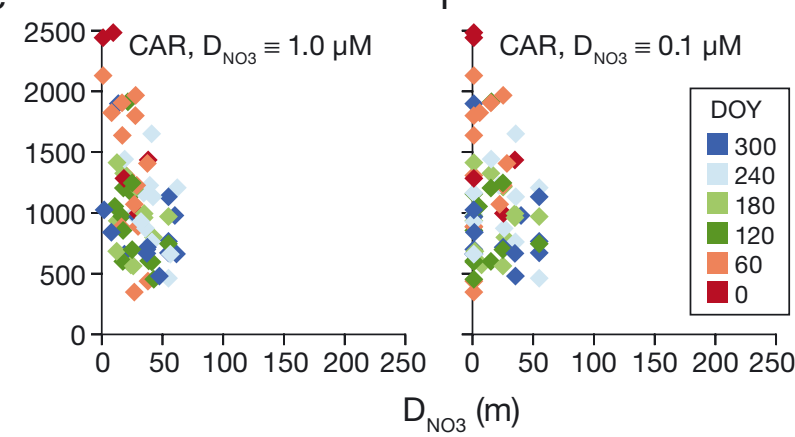

Fig. 7. Total PP from the $(\mathrm{a}, \mathrm{b}) \mathrm{HOT},(\mathrm{c}, \mathrm{d})$ BATS, and $(\mathrm{e}, \mathrm{f})$ CARIACO time series stations versus $\mathrm{D}_{\mathrm{NO} 3}$, defined by 2 different levels of nitrate concentrations $(\mathrm{a}, \mathrm{c}, \mathrm{e}: 1 \mu \mathrm{M} ; \mathrm{b}, \mathrm{d}, \mathrm{f}$ : $0.1 \mu \mathrm{M}$ ). The day of the year (DOY) of observations is shown with colors. Abbreviations as in Fig. 1

events of nutrient-rich water (Scranton et al. 2014). Changing the definition of the nutricline had no effect on the patterns in the plot (Fig. 7f). Peak PP is noted in the early part of the year, a period when upwelling events are frequent.

Comparison of these 3 stations suggests that the overlap of nutrient-rich waters with the euphotic zone ultimately controls the total PP occurring in the water column. In the very stable situation (HOT), the highest/lowest PP rates coincide with periods of highest/lowest insolation rates. At the 2 other stations, insolation is also clearly important, as the lowest PP rates coincide with periods of low insolation. However, mixing events that increase the overlap between nutrient-rich water and the euphotic zone during the first part of the year lead to the highest PP rates occurring here rather than at the time of the summer solstice.

\subsection{Vertical distribution of PP}

The pattern describing the vertical distribution of PP (expressed as percentage of total water column production occurring in the upper $10 \mathrm{~m}$ ) was also similar in our own (Fig. 6c) and the archived data (Fig. 6d). The shapes of the curves emerging from this analysis were similar to those describing total PP as a function of $\mathrm{D}_{\mathrm{NO} 3}$. When $\mathrm{D}_{\mathrm{NO} 3}$ is near the surface, up to $~ 80 \%$ of water column PP can occur in the upper $10 \mathrm{~m}$. However, variability in this fraction is large in the surface layer. This variability at the surface may, in part, be driven by sampling in HNLC regions, but local dynamics are likely also playing a role.

In contrast, when $\mathrm{D}_{\mathrm{NO} 3}$ is $>\sim 90 \mathrm{~m}$, the \% of PP occurring in the upper $10 \mathrm{~m}$ lies consistently below $20 \%$ in the combined set, in general accordance with the average value of $\gamma$ of $10.7 \%$ (Table 2) in our own data. One factor possibly contributing to the consistency in the fraction of PP occurring in the surface layer in these regions is that ocean areas where $\mathrm{D}_{\mathrm{NO} 3}$ is $>90 \mathrm{~m}$, i.e. the oligotrophic subtropical gyres, can be expected to be dynamically more similar (Pedlosky 1990) to one another than regions where $\mathrm{D}_{\mathrm{NO}}$ is found higher in the water column. Here, it is interesting to note that the 16 sampling sites in our own data set where $\mathrm{D}_{\mathrm{NO} 3}$ was $>90 \mathrm{~m}$ represent a wide geographic distribution (Sargasso Sea, Solomon Sea and eastern Atlantic, Southern, and Indian Oceans) and that the data points from these stations agree well with those from the HOT (central North Pacific) and BATS (Sargasso Sea) programmes, where there is full seasonal coverage. On this basis, we argue that the relatively constant result describing the fraction of water column PP occurring in the upper $10 \mathrm{~m}$ in oligotrophic regions is likely robust.

\subsection{Estimation of total global ocean PP from the identified pattern in vertical distribution of PP}

The total annual global PP in the surface $10 \mathrm{~m}$ of the global ocean (Fig. 8a) was estimated to be $12.1 \mathrm{Pg} \mathrm{C}$ $\mathrm{yr}^{-1}$ (Table 2). The major proportion of this $(\sim 75 \%)$ was produced in areas with a shallow nutricline $\left(\mathrm{D}_{\mathrm{NO}}\right.$ $<20 \mathrm{~m}$ ). Only $\sim 7 \%$ of the total PP occurring in the upper $10 \mathrm{~m}$ was generated in the extensive oligotrophic regions (i.e. $\mathrm{D}_{\mathrm{NO} 3}>90 \mathrm{~m}$ ) of the world's oceans.

The total annual PP in the water column for the period 2003-2013 (Fig. 8b) estimated by our VPP model was calculated from the scale factor $\gamma$, depending on the locally varying $\mathrm{D}_{\mathrm{NO} 3}$ during the model integration (Table 2). This calculation resulted in a 

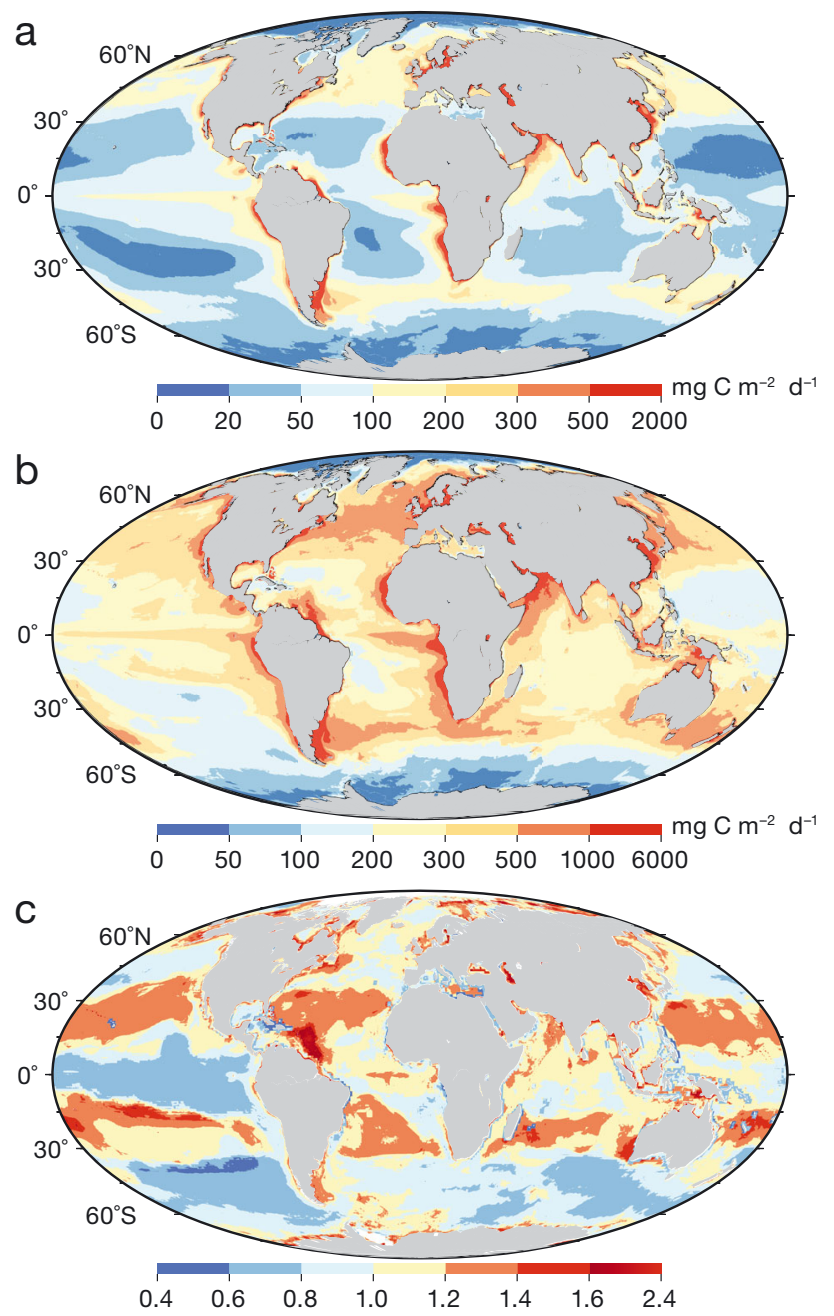

Fig. 8. Annual averaged primary production (PP) from 2003-2013. (a) PP in the upper $10 \mathrm{~m}$, (b) total vertical PP distribution (VPP) and (c) the ratio between the VPP model and the PP calculated from the VGPM model of Behrenfeld \& Falkowski (1997)

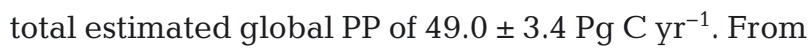
the above, it would then appear that PP occurring in the upper $10 \mathrm{~m}$ contributes $\sim 25 \%$ of total global ocean PP. The total PP estimate resulting from applying the VPP model is remarkably similar to the estimate for total global PP obtained from estimates made using the VGPM algorithm (Behrenfeld \& Falkowski 1997) for the same time period, i.e. $47.8 \pm$ 3.3 $\mathrm{Pg} \mathrm{C} \mathrm{yr}^{-1}$. However, the geographic distribution of PP is quite different when the 2 methods are applied. Our VPP estimate suggests that oligotrophic regions are more productive than estimated by VGPM. As a result, the VPP estimate suggests that the differences in PP between the most and least productive regions of the world's oceans is less than that indicated by VGPM.
Where the VGPM estimate of global PP ( $\mathrm{PP}_{\mathrm{VGPM}}$ ) suggests that regions with a shallow $(<20 \mathrm{~m}) \mathrm{D}_{\mathrm{NO} 3}$ contribute $\sim 5 \times$ more to global PP than regions where the $\mathrm{D}_{\mathrm{NO} 3}>90 \mathrm{~m}$, our VPP model suggests that the difference in contributions from these 2 regions is only a factor of $\sim 3$ (Table 2). This difference stems mainly from the fact that our VPP model indicates oligotrophic regions to be considerably more productive than is suggested by the VGPM. That PP in oligotrophic regions may be greater than normally assumed has also been suggested in other observational and model studies (e.g. Westberry et al. 2008, Emerson 2014).

\section{DISCUSSION}

This study demonstrates the presence of consistent patterns in the open ocean with respect to (1) the distribution of chl $a$ in the water column (position of the DCM), (2) total water column PP and (3) the vertical distribution of PP in relation to the depth of the nutricline. Recognition of these apparently universal patterns has potential importance both for estimating global ocean PP and for projecting climate change impacts on ocean PP.

The relationship between total water column PP and $\mathrm{D}_{\mathrm{NO} 3}$ opens the possibility of estimating ocean PP from light availability and nutricline depth. Real-time information regarding nutrient distributions in the ocean is becoming more readily available owing to a growing number of autonomous data collection platforms. Thus, estimating ocean PP on the basis of actual nutrient and light availability in the water column may soon become a reality.

The results of the analyses conducted here indicate that total PP occurring at any given site is a function of the overlap between nutrient-rich water and the euphotic zone and that total PP can be described as a function of nutrient depth. This implies that the depth of the nutricline is a critical factor to consider when projecting PP in an ocean impacted by climate change. How climate change may influence the depth of the nutricline is, however, currently unknown.

\section{1. $\mathrm{DCM}$ vs. $\mathrm{D}_{\mathrm{NO} 3}$}

That the values of the photosynthetic parameters describing the photosynthesis vs. light (P vs. E) relationship also show a relationship to $\mathrm{D}_{\mathrm{NO} 3}$ suggests eco-physiological factors are leading to the patterns demonstrated. In our own data, we found that, with 
only 1 exception, $\mathrm{D}_{\mathrm{NO} 3}$ was located above or very near to our estimate of the bottom of the euphotic zone, which suggests that $\mathrm{D}_{\mathrm{NO} 3}$ is closely related to nutrient uptake. No clear relationship between DCM and nutricline depth is found when $\mathrm{D}_{\mathrm{NO}}$ is shallower than $\sim 20 \mathrm{~m}$ in accordance with the understanding that phytoplankton activity may not be limited by inorganic nitrogen in the surface layer under these conditions. When the $\mathrm{D}_{\mathrm{NO} 3}$ is located between $\sim 20$ and $90 \mathrm{~m}$, the depths of the DCM and $\mathrm{D}_{\mathrm{NO} 3}$ apparently coincide. Other workers (Herbland \& Voituriez 1979, Cullen \& Eppley 1981, Beckmann \& Hense 2007, Brown et al. 2015) have also found the DCM and nutricline depths to be coincident at depths between $\sim 20$ and $\sim 100 \mathrm{~m}$ (deepest depth studied) in regional studies.

This juxtaposition of the DCM and $\mathrm{D}_{\mathrm{NO} 3}$ might lead us to predict a higher ratio of new/regenerated production (Dugdale \& Goering 1967) occurring in the vicinity of the DCM than higher up in the water column, where a greater dependence on regenerated nitrogen would seem likely. Indeed, this has been a finding in several studies examining characteristics of water column photosynthesis (Weston et al. 2005, Fernand et al. 2013). If this is a consistent feature of water column photosynthesis, then PP occurring at the DCM may be more important for the net production of organic material and oxygen than the PP occurring at shallower depths in the water column.

A novel facet of the analyses presented here is that when $\mathrm{D}_{\mathrm{NO}}$ is deep, i.e. $>\sim 90 \mathrm{~m}$, all of the data sets examined indicate that the DCM is consistently found above the nutricline. This suggests that the position of the DCM may be controlled by light availability. Remaining deep in the water column, i.e. close to the nutricline, would presumably maximise the probability of nutrient delivery to the DCM through vertical mixing processes (Richardson \& Bendtsen 2017). This interpretation is supported by the results of Fawcett et al. (2014), who found the greatest contribution to new $\mathrm{PP}$ in Sargasso Sea $\left(\mathrm{D}_{\mathrm{NO} 3}>90 \mathrm{~m}\right)$ water columns to be associated with eukaryotes in the DCM. Further support for this interpretation is found in Fig. 7, where the highest rates of PP are associated with episodic mixing events at the BATS and CARIACO stations.

To examine the potential role of light availability in driving the deviation of DCM depth and $\mathrm{D}_{\mathrm{NO} 3}$ deep in the water column, we used the simple diffusive vertical balance model described in Eq. (3). Analysing the equation shows that when turbulent mixing is low, i.e. a small $k_{\mathrm{v}}, \mathrm{D}_{\mathrm{NO} 3}$ and DCM converge, whereas they tend to diverge when mixing increases. Correspondingly, when PP decreases, as for example when
PP is light limited at depth in the water column, $\mathrm{D}_{\mathrm{NO}}$ and DCM diverge. The opposite is the case when PP is high, i.e. a large PP tends to reduce the distance between $\mathrm{D}_{\mathrm{NO} 3}$ and the DCM. It should also be noted that, as $f_{\mathrm{PP}}$ decreases, corresponding to a decreasing export ratio, the 2 depth levels diverge and eventually become decoupled.

Model solutions for 2 values of turbulent mixing showed a general accordance with observations (Fig. 3). The chlorophyll profile used in the model describes a typical situation in subtropical gyres where nutrient fluxes due to a vertical turbulent background mixing are small (e.g. Ledwell et al. 1993) but where mixing is episodically enhanced by passing baroclinic eddies or other transient phenomena. These mixing events can supply the euphotic zone with nutrients for new production (e.g. Lipschultz et al. 2002, Johnson et al. 2010). A simple vertical balance is only representative on relatively short time scales because large-scale lateral transports of both nutrients and dissolved organic matter are important for the subtropical biogeochemical cycling (Jenkins \& Doney 2003). However, because the phytoplankton community responds to nutrient supplies on time scales of days to weeks, it is relevant to analyse this balance as we do here in areas characterised by very low nutrient concentrations in the euphotic zone.

Studies have shown that the chl:C ratio in oligotrophic regions may increase significantly with depth (e.g. Fennel \& Boss 2003), thereby increasing the light-harvesting potential per carbon unit. However, this dependence of the chl:C ratio with depth does not influence our estimate of PP in Eq. (2), as the equation is only dependent on the chlorophyll distribution and the measured photosynthetic parameters. Increased phytoplankton $\mathrm{C}: \mathrm{N}$ ratios have been observed in oligotrophic areas (Martiny et al. 2013). Such an increase in C:N ratios would lead to larger separation according to Eq. (3) than calculated from the applied Redfield ratio of 6.6 but would not alter the overall conclusion generated from the model. Thus, although the vertical diffusive balance model contains several simplifying assumptions, the model can explain the general divergence of the depth of the $\mathrm{DCM}$ and $\mathrm{D}_{\mathrm{NO} 3}$ as being due to light limitation and a resulting reduction in $\mathrm{PP}$ when $\mathrm{D}_{\mathrm{NO} 3}$ depths are greater than $\sim 90 \mathrm{~m}$.

\subsection{Conclusions}

This study demonstrates a relationship between both total PP and the vertical distribution of PP and 
nutricline depth. Nutricline depth is related to water column stratification. As water column stratification characteristics are obvious candidates for change in a warming ocean, climate change may induce changes in nutricline depth that will, in turn, have implications for global ocean PP. The apparently universal relationship between the vertical distribution of PP and nutricline depth identified here potentially provides opportunities for more explicit depiction of the interaction between nutrient and light availability in controlling phytoplankton activity in ecosystem models as well as for directly incorporating nutrient availability as a parameter in the estimation of PP in the global ocean.

Acknowledgements. The data collection for this study was carried out as part of the Galathea3 Expedition under the auspices of the Danish Expedition Foundation and was supported by the Villum Kann Rasmussen Foundation, the Nordea Foundation and the Danish Research Council for Nature and Universe. Analyses were supported by the Danish National Science Foundation via its support of the Center for Macroecology, Evolution, and Climate (grant no. DNRF96). This is Galthea3 contribution no. P126.

\section{LITERATURE CITED}

Beckmann A, Hense I (2007) Beneath the surface: characteristics of oceanic ecosystems under weak mixing conditions - a theoretical investigation. Prog Oceanogr 75: 771-796

Behrenfeld MJ, Falkowski PG (1997) Photosynthetic rates derived from satellite-based chlorophyll concentration. Limnol Oceanogr 42:1-20

Boyer TP, Antonov JI, Baranova OK, Coleman C and others (2013) World Ocean Database. NOAA Atlas NESDIS 72. Silver Spring, MD

Brown ZW, Lowry KE, Palmer MA, van Dijken GL, Mills MM, Pickart RS, Arrigo KR (2015) Characterizing the subsurface chlorophyll a maximum in the Chukchi Sea and the Canada Basin. Deep Sea Res II 118:88-104

Cabré A, Marinov I, Leung S (2015) Consistent global responses of marine ecosystems to future climate change across the IPCC AR5 earth system models. Clim Dyn 45: $1253-1280$

Cullen JJ (1982) The deep chlorophyll maximum: comparing vertical profiles of chlorophyll $a$. Can J Fish Aquat Sci 39:791-803

Cullen JJ (2015) Subsurface chlorophyll maximum layers: enduring enigma or mystery solved? Annu Rev Mar Sci $7: 207-239$

Cullen JJ, Eppley RW (1981) Chlorophyll maximum layers of the Southern California Bight and possible mechanisms of their formation and maintenance. Oceanol Acta 4:24-32

* Dugdale RC, Goering JJ (1967) Uptake of new and regenerated forms of nitrogen in primary productivity. Limnol Oceanogr 12:196-206

Emerson S (2014) Annual net community production and the biological carbon flux in the ocean. Global Biogeochem Cycles 28:14-28
Fawcett SE, Lomas MW, Ward BB, Sigman DM (2014) The counter-intuitive effect of summer-to-fall mixed layer deepening on eukaryotic new production in the Sargasso Sea. Global Biogeochem Cycles 28:86-102

Fennel K, Boss E (2003) Subsurface maxima of phytoplankton and chlorophyll: steady-state solutions from a simple model. Limnol Oceanogr 48:1521-1534

Fernand L, Weston K, Morris T, Greenwood N, Brown J, Jickells T (2013) The contribution of the deep chlorophyll maximum to primary production in a seasonally stratified shelf sea, the North Sea. Biogeochemistry 113:153-166

Fujieki LA, Santiago-Mandujano F, Fitgzgerald D, Lethaby P, Lukas R, Karl D (2007) Hawaii Ocean Time-series Program Data Rep 19. School of Ocean and Earth Science and Technology, University of Hawaii, Honolulu, HI

Garcia HE, Locarnini RA, Boyer TP, Antonov JI and others (2010) World Ocean Atlas 2009, Vol 4: Nutrients (phosphate, nitrate, silicate). NOAA Atlas NESDIS 71. U.S. Government Printing Office, Washington, DC

Herbland A, Voituriez B (1979) Hydrological structure analysis for estimating the primary production in the tropical Atlantic Ocean. J Mar Res 37:87-101

*Hickman AE, Moore CM, Sharples J, Lucas MI, Tilstone GH, Krivtsov V, Holligan PM (2012) Primary production and nitrate uptake within the seasonal thermocline of a stratified shelf sea. Mar Ecol Prog Ser 463:39-57

*Hilligsøe KM, Richardson K, Bendtsen J, Sørensen LL, Nielsen TG, Lyngsgaard MM (2011) Linking phytoplankton community size composition with temperature, plankton food web structure and sea-air $\mathrm{CO}_{2}$ flux. Deep Sea Res I 58:826-838

Jenkins WJ, Doney SC (2003) The subtropical nutrient spiral. Global Biogeochem Cycles 17:1110

Johnson KS, Riser SC, Karl DM (2010) Nitrate supply from deep to near-surface waters of the North Pacific subtropical gyre. Nature 465:1062-1065

Karl DM, Lukas R (1996) The Hawaii Ocean Time-series (HOT) program: background, rationale and field implementation. Deep Sea Res II 43:129-156

Klausmeier C, Litchman E (2001) Algal games: the vertical distribution of phytoplankton in poorly mixed water columns. Limnol Oceanogr 46:1998-2007

KLedwell JR, Watson AJ, Law CS (1993) Evidence for slow mixing across the pycnocline from an open-ocean tracerrelease experiment. Nature 364:701-703

Lipschultz F, Bates NR, Carlson CA, Hansell DA (2002) New production in the Sargasso Sea: history and current status. Global Biogeochem Cycles 16:1001

* Lomas MW, Bates NR, Johnson RJ, Knap AH, Steinberg DK, Carlson CA (2013) Two decades and counting: 24-years of sustained open ocean biogeochemical measurements in the Sargasso Sea. Deep Sea Res II 93:16-32

Luyten PJ, Jones JE, Proctor R, Tabor A, Tett P, Wild-Allen K (1999) COHERENS - A coupled hydrodynamical-ecological model for regional and shelf seas: user documentation. MUMM Rep. Management Unit of the Mathematical Models of the North Sea, Brussels

* Lyngsgaard MM, Markager S, Richardson K (2014) Changes in the vertical distribution of primary production in response to land-based nitrogen loading. Limnol Oceanogr 59:1679-1690

Martin J, Dumont D, Tremblay JE (2013) Contribution of subsurface chlorophyll maxima to primary production in the coastal Beaufort Sea (Canadian Arctic): a model assessment. J Geophys Res 118:5873-5886 
Martiny AC, Vrugt JA, Primeau FW, Lomas MW (2013) Regional variation in the particulate organic carbon to nitrogen ratio in the surface ocean. Global Biogeochem Cycles 27:723-731

Morel A, Huot Y, Gentili B, Werdell BJ, Hooker SB, Franz BA (2007) Examining the consistency of products derived from various ocean color sensors in open ocean (Case 1) waters in the perspective of a multi-sensor approach. Remote Sens Environ 111:69-88

Pedlosky J (1990) The dynamics of the oceanic sub-tropical gyres. Science 248:316-322

Richardson K (1991) Comparison of ${ }^{14} \mathrm{C}$ primary production determinations made by different laboratories. Mar Ecol Prog Ser 72:189-201

Richardson K, Bendtsen J (2017) Photosynthetic oxygen production in a warmer ocean: The Sargasso Sea as a case study. Philos Trans R Soc A 375:20160329

Richardson K, Beardall J, Raven JA (1983) Adaptation of unicellular algae to irradiance: an analysis of strategies. New Phytol 93:157-191

Richardson K, Markager S, Buch E, Lassen MF, Kristensen A (2005) Seasonal distribution of primary production, phytoplankton biomass and size distribution in the Greenland Sea. Deep Sea Res I 52:979-999

Richardson K, Bendtsen J, Christensen JT, Adjou M and others (2014) Localised mixing and heterogeneity in the plankton food web in a frontal region of the Sargasso

Editorial responsibility: Robinson Fulweiler, Boston, Massachusetts, USA
Sea: implications for eel early life history? Mar Ecol Prog Ser 504:91-107

Richardson K, Bendtsen J, Kragh T, Mousing EA (2016) Constraining the distribution of photosynthetic parameters in the global ocean. Front Mar Sci 3:269

* Scranton MI, Taylor GT, Thunell R, Benitez-Nelson CR and others (2014) Interannual and subdecadal variability in the nutrient geochemistry of the Cariaco Basin. Oceanography 27:148-159

Steemann Nielsen E (1952) The use of radio-active carbon $\mathrm{C}^{14}$ for measuring organic production in the sea. J Cons Int Explor Mer 18:117-140

Steinberg DK, Carlson CA, Bates NR, Johnson RJ, Michaels AF, Knap AH (2001) Overview of the US JGOFS Bermuda Atlantic Time-series Study (BATS): a decadescale look at ocean biology and biogeochemistry. Deep Sea Res II 48:1405-1447

Webb WL, Newton M, Starr D (1974) Carbon dioxide exchange of Alnus rubra. A mathematical model. Oecologia 17:281-291

Westberry TK, Behrenfeld MJ, Siegel, DA, Boss, E (2008) Carbon-based primary production modeling with vertically resolved photoaccumulation. Glob Biogeochem Cycles 22:GB2024

*Weston K, Fernand L, Mills DK, Delahunty R, Brown J (2005) Primary production in the deep chlorophyll maximum of the central North Sea. J Plankton Res 27:909-922

Submitted: January 30, 2019; Accepted: April 5, 2019

Proofs received from author(s): May 28, 2019 